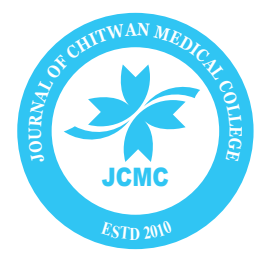

\author{
Journal of Chitwan Medical College 2019;9(30):2-5 \\ Available online at: www.jcmc.cmc.edu.np
}

\title{
DETERMINATION \& COMPARISON OF MAXILLARY FIRST PREMOLAR PULP CHAMBER LANDMARKS USING INTRAORAL PERIAPICAL RADIOGRAPH AND CONE-BEAM COMPUTED TOMOGRAPHY \\ Neera Joshi ${ }^{1, *}$, Kranti Prajapati ${ }^{1}$, Suraj Shrestha ${ }^{1}$, Sharada Wagle ${ }^{1}$ \\ ${ }^{1}$ Department of Conservative and Endodontics, People's Dental College and Hospital, Sorakhutte, Kathmandu Nepal.
}

\begin{abstract}
Received: 30 Aug, 2019
Accepted: 27 Nov, 2019

Published: 27 Dec, 2019

Key words: $\mathrm{CBCT}$; Furcation; IOPA; Perforation; Pulp chamber.

*Correspondence to: Neera Joshi, Department of Conservative and Endodontics, People's Dental College and Hospital, Sorakhutte, Kathmandu Nepal. Email: neera_ktm@yahoo.com

DOI:https://doi.org/10.3126/jcmc.v9i4.26889

Citation

Joshi N, Prajapati K, Shrestha S, Wagle S. Determination and comparison of maxillary first premolar pulp chamber landmarks using intraoral periapical radiograph and cone-beam computed tomography.2019;9(30):2-5
\end{abstract}

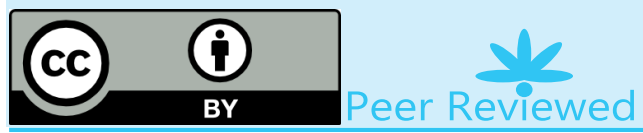

\section{INTRODUCTION}

The importance of access cavity has been mentioned as 'the gateway of root canal'. ${ }^{1}$ Conservative access cavity further enhances the fracture resistance of the tooth. ${ }^{2,3}$. Knowing dimension and location of pulp cavity during access cavity preparation helps clinician in instruments selection, orientation and depth of cutting during preparation. ${ }^{1,4}$ Analysis of dimension and location of pulp cavity has been carried from the early days with preoperative intra-oral periapical (IOPA) radiograph, ${ }^{5}$ which gives two-dimensional image of threedimensional object. There has been number of studies that show dimension taken from radiograph varies considerably, due to which access cavity preparation may be compromised, and iatrogenic damages may occur. However, paralleling technique in periapical radiograph is said to have reasonably approximate measurement ${ }^{6}$ Recently, Cone-Beam Computed Tomography (CBCT) has become a valuable tool for the practice of endodontics where measurement and calculation of pulp spaces may provide more precise anatomic information., Such information may assist in achieving proper and precise access cavity preparation and minimizing iatrogenic damages. ${ }^{9}$

Although CBCT has high accuracy, it is not used routinely in every clinical scenario. IOPA radiograph remains the valid option as being easily available and economical. Hence, this in-vitro study was aimed to determine the pulp chamber landmarks of maxillary first premolar using IOPA radiograph and CBCT and compare the measurement from these landmarks.

\section{METHODS}

Fifty extracted maxillary first premolar teeth were collected from oral surgery department, Peoples Dental College. The selected teeth were free of caries, had two roots, had intact cusps, had closed apex, and had no attrition. All the selected teeth were thoroughly cleaned and disinfected by immersing them into $10 \%$ formalin for 7 days. Each tooth was assigned a number, with permanent marker (Cello Permaline) on the palatal surface of crown, from 1 to 50. Teeth (1 to 50) were radiographed using intraoral film (E-speed, Carestream Dental) and Gendex X-ray with parallel technique. The film was placed on X-ray viewer. Tracing paper was placed over the film and four landmarks were marked. The images thus acquired were named group I.

Two blocks of $23 \mathrm{~cm}$ length, $1 \mathrm{~cm}$ breadth and $2 \mathrm{~cm}$ height in horseshoe shaped were fabricated with modeling wax. 25 
teeth, separated from each other by $2 \mathrm{~mm}$, were mounted by embedding the root portion in each wax rim. Metal pin was attached to each wax block, $50 \mathrm{~mm}$ away from tooth. The wax block that contained the teeth numbered 1 to 25 was placed on the bite mount of CBCT (Planmeca) and the other wax block that contained the teeth numbered 26 to 50 was placed over the first wax block (Fig.1). Scanning was performed with ProMax 3D CBCT (Planmeca) operated at $90 \mathrm{kV}, 14 \mathrm{~mA}$ with a voxel size of $200 \mu \mathrm{m}$ and a field of view of 90 by150 mm. The CBCT image was opened in Planmeca Romexis software. Each tooth (tooth numbered 1 to 50) was identified and four landmarks were marked. The images thus acquired were named group II.

The four landmarks were named as L1, L2, L3 and L4. L1 was the mid-point of a line connecting two cusp tips; L2 was the lowest point on roof of the pulp chamber; L3 was the highest point on floor of the pulp chamber; and L4 was the point of complete separation at furcation. A horizontal line was drawn from each landmark parallel to each other. Six measurements in millimeter $(\mathrm{mm})$ were taken from these landmarks' lines. The six measurements were named as A, B, C, D, E and F. A is the distance between L1 to L2. B is the distance between L1 to L3. C is the distance between L1 to L4. D is the distance obtained by subtracting $B$ from $C$, i.e. the distance between $\mathrm{L} 3$ to $L 4$. $E$ is the distance obtained by subtracting $A$ from $C$, i.e. the distance between $L 2$ to $L 4$. F is the distance obtained by subtracting A from B, i.e. distance between L2 to L3 (Fig.2).

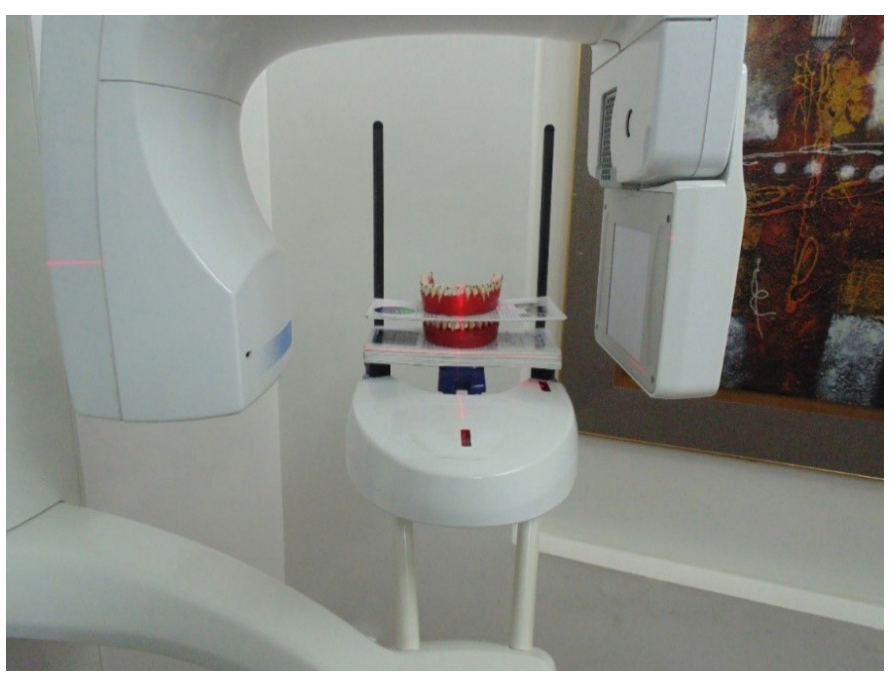

Figure 1: Scanning with СВCT

$$
\begin{array}{ll}
A=L 1 \text { to } L 2 & D=C-B(L 3 \text { to } L 4) \\
B=L 1 \text { to } L 3 & E=C-A(L 2 \text { to } L 4)
\end{array}
$$

Data were collected, compiled and analyzed by using Statistical Package of Social Science (SPSS) software version 16. The data were expressed as mean \pm SD. The mean comparisons of six measurements between IOPA and CBCT groups were done by independent t-test. $p$-value of $<0.05$ was considered to be statistically significant.

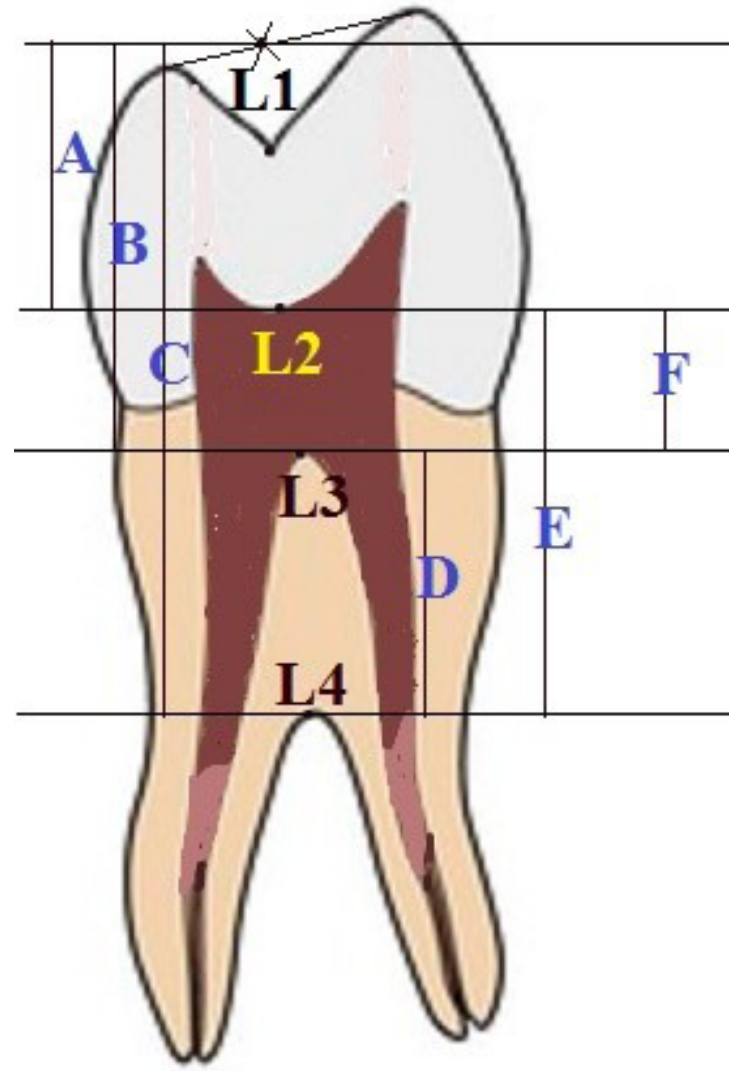

Figure 2: Location of measurements for maxillary first premolar.

\section{RESULTS}

The average distance from the cusp tip to the pulp chamber roof $(A)$ and floor $(B)$ as recorded by IOPA was $7.44 \pm 1.07 \mathrm{~mm}$ and $10.23 \pm 1.13 \mathrm{~mm}$ respectively. The distance between the cusp tips to closest point in furcation (C) was recorded to be $14.33 \pm 1.34$. $\mathrm{mm}$.The mean distance between floor (D) of the pulp chamber and roof (E) of the chamber was $4.10 \pm 1.78 \mathrm{~mm}$ and $6.89 \pm 1.40 \mathrm{~mm}$ respectively. The average height of the pulp chamber $(F)$ was $2.79 \pm 0.70 \mathrm{~mm}$.

The average distance from the cusp tip to the pulp chamber roof $(A)$ and floor (B) as recorded by CBCT was $6.95 \pm 0.64$ and $9.58 \pm 0.84 \mathrm{~mm}$ respectively. The distance between the cusp tips to closest point in furcation (C) was recorded to be $14.03 \pm 1.44 \mathrm{~mm}$. The mean distance between floor $(D)$ of the pulp chamber and roof (E) of the chamber was $4.45 \pm 1.64$ and $7.07 \pm 1.44 \mathrm{~mm}$ respectively. The average height of the pulp chamber $(F)$ was $2.63 \pm 0.75 \mathrm{~mm}$.

The mean values of two measurements i.e. A and B showed significant difference when IOPA was compared to CBCT. The results show that mean values of distance from cusp tip to pulp chamber roof (A) and cusp tip to pulp chamber floor (B) recorded by IOPA was higher than CBCT which was statistically significant with $\mathrm{p}$ value less than 0.05 . 
Table 1: Comparison of various morphological measurements recorded from IOPA and CBCT.

\begin{tabular}{|l|l|l|l|l|l|l|}
\hline Measurements & $\begin{array}{l}\text { IOPA (mean } \pm \\
\text { sd) }\end{array}$ & $\begin{array}{l}\text { CBCT (mean } \pm \\
\text { sd) }\end{array}$ & Mean diff. & 95\% Cl of diff. & p value \\
\cline { 3 - 6 } & & $6.95 \pm 0.64$ & 0.486 & 0.133 & 0.838 & $0.007^{*}$ \\
\hline $\begin{array}{l}\text { Cusp tip to pulp } \\
\text { chamber roof } \\
\text { (A) }\end{array}$ & $7.44 \pm 1.07$ & & & & & \\
\hline $\begin{array}{l}\text { Cusp tip to pulp } \\
\text { chamber floor } \\
\text { (B) }\end{array}$ & $10.23 \pm 1.13$ & $9.58 \pm 0.84$ & 0.649 & 0.251 & 1.046 & $0.002^{*}$ \\
\hline $\begin{array}{l}\text { Cusp tip to the } \\
\text { furcation (C) }\end{array}$ & $14.33 \pm 1.34$ & $14.03 \pm 1.44$ & 0.3 & -0.252 & 0.852 & 0.284 \\
\hline $\begin{array}{l}\text { Floor of pulp } \\
\text { chamber to } \\
\text { furcation(D) }\end{array}$ & $4.10 \pm 1.47$ & $4.45 \pm 1.64$ & -0.349 & -0.969 & 0.271 & 0.267 \\
\hline $\begin{array}{l}\text { Roof of pulp } \\
\text { chamber to } \\
\text { furcation(E) }\end{array}$ & $6.89 \pm 1.40$ & $7.07 \pm 1.44$ & -0.186 & -0.749 & 0.377 & 0.514 \\
\hline $\begin{array}{l}\text { Height of pulp } \\
\text { chamber (F) }\end{array}$ & $2.79 \pm 0.70$ & $2.63 \pm 0.75$ & 0.163 & -0.125 & -0.451 & 0.265 \\
\hline
\end{tabular}

*statistically significant.

\section{DISCUSSION}

A sound knowledge regarding pulp chamber anatomy, dimension and location is very essential before initiating root canal therapy so as to prepare proper access cavity, to find canal orifice at appropriate position, to reduce tooth destruction and to prevent undesirable iatrogenic damage of pulp floor. Review of literature has shown very few studies that measure anatomic landmarks relating to the pulp chamber of furcated maxillary first premolars. Previously, measurement of the landmarks by sectioning of the tooth was done. ${ }^{10.13}$ Krasner and Rankow, however, described anatomical pattern and relationships of pulp chamber floor. ${ }^{14}$

Endodontic access cavity preparation is determined by internal pulp chamber anatomy. The extension of internal pulp chamber anatomy guides us in deroofing the pulp chamber as it is necessary for accessibility to the coronal and radicular root canal system. ${ }^{15} \mathrm{CBCT}$ is used for diagnosis and management of complex endodontic problem since it gives a three-dimensional radiographic image. ${ }^{16}$ Three-dimensional CBCT may provide higher accuracy and a greater amount of information than two-dimensional imaging modalities while doing endodontic procedure and endodontic surgery. ${ }^{17}$

The peaks of these extension are the landmarks that need to be identified before initiating treatment for preventing the iatrogenic damage in the floor and walls of pulp chamber. ${ }^{18}$ Hence, midpoint of line connecting two cusp tips, lowest point on roof of the pulp chamber, highest point on floor of the pulp chamber, and complete separation at furcation were chosen as landmarks to measure the extension of pulp chamber. Deutsch et al in his study, had also taken same landmarks for measurements in maxillary furcated bicuspids. ${ }^{19}$. Azim et al in his study, had chosen cusp tip, central fossa, roof and floor of the pulp chamber and complete separation at furcation as landmarks for measurements in maxillary and mandibular molars. ${ }^{9}$ In the present study, mesio-distal view of tooth was selected for IOPA exposure, so that both cusp tips and the furcation were seen in an image. This also allowed for direct morphological measurements relating to the furcation. ${ }^{19}$

For exposure of samples using $\mathrm{CBCT}$, teeth were mounted in a wax rim to scan all the teeth in a single exposure. Metal pin in wax rim identified the sequence of tooth placement. Pin was placed $50 \mathrm{~mm}$ away from tooth, so that, it could not interfere with the image. Study evaluating the degree of metal artifacts by CBCT had found no artifacts when metal was beyond 5 $\mathrm{cm}$ from interest site. ${ }^{20} \mathrm{CBCT}$ images were numbered for identification purpose.

Comparing the results of present study from Deutch et al, measurement A, C, D, E \& F appeared to be $0.5 \mathrm{~mm}, 2.78 \mathrm{~mm}$, $2.25 \mathrm{~mm}, 2.28 \mathrm{~mm} \& 0.03 \mathrm{~mm}$ longer respectively in IOPA radiographic image, and measurement $A, C, D \& E$ appeared to be $0.01 \mathrm{~mm}, 2.48 \mathrm{~mm}, 2.6 \mathrm{~mm} \& 2.46 \mathrm{~mm}$ longer respectively in CBCT image. ${ }^{17}$ The difference in quantitative measurement of the anatomic landmarks in pulp chamber of maxillary first premolar in comparison to study conducted by Deutch et al. in Tennessee population could be attributed to racial difference, since the present study was carried out in Nepalese population. However, Deutch et al. used RVG, a digital image, for IOPA radiograph. ${ }^{19}$

When comparing the results of IOPAR and $C B C T$, there was a significant difference in measurement of $A$ and $B$. It is possible that variation in IOPA radiographic measurement could be responsible for limitation of images like distortion and artifact. 
The result showed the measurements of IOPA radiographic image are higher than $C B C T$ image. This might indicate chances of overestimation in $A$ and $B$ in IOPA radiographic image which might result in iatrogenic damage during access cavity preparation.

The study done on this limited subject might not represent the whole population.

\section{CONCLUSION}

The result showed, the measurement $A$ and $B$ from IOPA was

\section{REFERENCES:}

1. Venkateshbabu N, Velmurugan N, Roy A, Kandaswamy D. Evaluation of the pulp chamber morphological measurements in maxillary first premolar in Indian population-an in-vitro study. Journal of Conservative Dentistry. 2007;10(4):119.

2. Trope M, Maltz DO, Tronstad L. Resistance to fracture of restored endodontically treated teeth. Dental Traumatology. 1985;1(3):108-11.[DOI]

3. Krishan R, Paqué $F$, Ossareh A, Kishen A, Dao T, Friedman S. Impacts of conservative endodontic cavity on root canal instrumentation efficacy and resistance to fracture assessed in incisors, premolars, and molars. Journal of endodontics. 2014;40(8):1160-6. [DOI]

4. Castellucci A. Access cavity and endodontic anatomy. Endodontics. 2004;1:245-329. Sherwood IA. Pre-operative diagnostic radiograph interpretation by general dental practitioners for root canal treatment. Dentomaxillofacial Radiology. 2012;41(1):43-54.

5. Forsberg J. Radiographic reproduction of endodontic "working length" comparing the paralleling and the bisecting-angle techniques. Oral Surgery, Oral Medicine, Oral Pathology. 1987;64(3):353-60. [DOI]

6. Lascala C, Panella J, Marques MM. Analysis of the accuracy of linear measurements obtained by cone beam computed tomography (CBCT-NewTom). Dentomaxillofacial Radiology. 2004;33(5):291-4. [DOI]

7. Honey OB, Scarfe WC, Hilgers MJ, Klueber K, Silveira AM, Haskell BS, et al. Accuracy of cone-beam computed tomography imaging of the temporomandibular joint: comparisons with panoramic radiology and linear tomography. American journal of orthodontics and dentofacial orthopedics. 2007;132(4):429-38. [DOI]

8. Azim AA, Azim KA, Deutsch AS, Huang GT-J. Acquisition of anatomic parameters concerning molar pulp chamber landmarks using cone-beam computed tomography. Journal of endodontics. 2014;40(9):1298-302. [DOI]

9. Sterrett $J D$, Pelletier $H$, Russell $C M$. Tooth thickness at the furcation entrance of lower molars. Journal of clinical periodontology. higher than from $\mathrm{CBCT}$ indicating that instead of $\mathrm{CBCT}$ if we rely on IOPA, there are chances of overestimation in $A$ and $B$. In general, the distance from cusps tip to the pulp chamber floor is approximately ten millimeters and cusp tip to the furcation is fourteen millimeters. Therefore, marking the bur at approximately ten millimeters will reduce the possibility of iatrogenic damage in pulpal floor.

\section{CONFLICT OF INTEREST}

None

\section{FINANCIAL DISCLOSURE}

None

$$
\text { 1996;23(7):621-7. [DOI] }
$$

10. Stambaugh RV, Wittrock JW. The relationship of the pulp chamber to the external surface of the tooth. The Journal of prosthetic dentistry. 1977;37(5):537-46. [DOI]

11. Scotti R, Villa L, Carossa S. Clinical applicability of the radiographic method for determining the thickness of calcified crown tissues. The Journal of prosthetic dentistry. 1991;65(1):65-7. [DOI]

12. Majzoub Z, Kon S. Tooth morphology following root resection procedures in maxillary first molars. Journal of periodontology. 1992;63(4):290-6. [DOI]

13. Krasner P, Rankow HJ. Anatomy of the pulp-chamber floor. Journal of endodontics. 2004;30(1):5-16. [DOI]

14. Rampado ME, Tjäderhane L, Friedman S, Hamstra SJ. The benefit of the operating microscope for access cavity preparation by undergraduate students. Journal of endodontics. 2004;30(12):863-7. [DOI]

15. S. Patel1,2 , J. Brown3, T. Pimentel1 , R. D. Kelly1, F. Abella4 \& C. Durack5 Cone beam computed tomography in Endodontic-are view of the literature, a review of the literature . International Endodontic Journal ,2019,52,1138-1152, doi:10.1111/iej.13115

16. JuliaC. Schmidt, Claudia-Julie Gutekunst, Dorothea Dagassan-Berndt , Patrick R. Schmidlin and Clemens Walter, Comparison of Two-Dimensional and Three-Dimensiona IRadiographs Using Clinically Relevant Julia C. Schmidt 1, dent.J.2019,7.50

17. Tsesis I, Fuss Z. Diagnosis and treatment of accidental root perforations. Endodontic Topics. 2006;13(1):95-107. [DOI]

18. Deutsch AS, Musikant BL, Gu S, Isidro M. Morphological measurements of anatomic landmarks in pulp chambers of human maxillary furcated bicuspids. Journal of endodontics. 2005;31(8):570-3. [DOI]

19. Nardi C, Borri C, Regini F, Calistri L, Castellani A, Lorini C, et al. Metal and motion artifacts by cone beam computed tomography (CBCT) in dental and maxillofacial study. La radiologia medica. 2015;120(7):618-26. 